\title{
Oral L-citrulline supplementation enhances cycling time trial performance in healthy trained men: Double-blind randomized placebo-controlled 2-way crossover study
}

\author{
Takashi Suzuki ${ }^{1}$, Masahiko Morita', Yoshinori Kobayashi ${ }^{2}$ and Ayako Kamimura ${ }^{1 *}$
}

\begin{abstract}
Background: Many human studies report that nitric oxide (NO) improves sport performance. This is because NO is a potential modulator of blood flow, muscle energy metabolism, and mitochondrial respiration during exercise. $\mathrm{L}$-Citrulline is an amino acid present in the body and is a potent endogenous precursor of L-arginine, which is a substrate for NO synthase. Here, we investigated the effect of oral L-citrulline supplementation on cycling time trial performance in humans.
\end{abstract}

Methods: A double-blind randomized placebo-controlled 2-way crossover study was employed. Twenty-two trained males consumed $2.4 \mathrm{~g} /$ day of L-citrulline or placebo orally for 7 days. On Day 8 they took $2.4 \mathrm{~g}$ of L-citrulline or placebo $1 \mathrm{~h}$ before a 4-km cycling time trial. Time taken to complete the $4 \mathrm{~km}$ cycle, along with power output $\mathrm{NO}_{2}$ ratio $\left(\mathrm{PO} N \mathrm{~N}_{2}\right)$, plasma nitrite and nitrate (NOx) and amino acid levels, and visual analog scale (VAS) scores, was evaluated.

Results: L-Citrulline supplementation significantly increased plasma L-arginine levels and reduced completion time by $1.5 \%(p<0.05)$ compared with placebo. Moreover, L-citrulline significantly improved subjective feelings of muscle fatigue and concentration immediately after exercise.

Conclusions: Oral L-citrulline supplementation reduced the time take to complete a cycle ergometer exercise trial.

Trial registration: Current Controlled Trials UMIN000014278.

Keywords: Ergogenic, Human, L-Citrulline, Nitric oxide (NO), Sport performance

\section{Background}

NO plays key roles such as maintaining the function and integrity of the endothelium, including vascular tone and structure [1]. In sports physiology, nitrate supplementation is thought to be an ergogenic aid [2-4]. This view is based on evidence that NO is an important modulator of blood flow and mitochondrial respiration under physiological conditions [5]. Some studies have shown that dietary NO related supplements, such as nitraterich beetroot juice, enhance human sport performance

\footnotetext{
* Correspondence: ayako.kamimura@kyowa-kirin.co.jp

'Healthcare Products Development Center, KYOWA HAKKO BIO CO., LTD., 2, Miyukigaoka, Tsukuba, Ibaraki 305-0841, Japan

Full list of author information is available at the end of the article
}

[6-9]. Dietary supplementation with nitrate thus appears to be beneficial for exercise.

There is growing interest in the use of L-citrulline as an NO-related dietary ingredient. L-Citrulline is present in the body and is a potent endogenous precursor of L-arginine [10], which is a substrate for NO synthase (NOS). NOS catalyzes a complex enzymatic reaction that leads to $\mathrm{NO}$ formation from L-arginine and oxygen and generates L-citrulline as a byproduct [11]. L-Citrulline is effectively recycled via the L-citrulline NO cycle to L-arginine and plays an important role in the metabolism and regulation of NO [12]. L-Citrulline supplementation has various beneficial effects, such as ameliorating arterial stiffness [13] and improving erectile function [14], memory [15], $\mathrm{O}_{2}$ uptake kinetics, and high- 
intensity exercise performance [16] through upregulation of NO synthesis. We and others have demonstrated in animal models that oral supplementation with L-citrulline upregulates endothelial NO synthase (eNOS) expression, improves endothelial function, and plays an atheroprotective role [17-19]. Interestingly, a clinical trial has shown that oral intake of L-citrulline dose-dependently and more effectively increases plasma L-arginine levels than does Larginine supplementation in healthy human volunteers [20]. Therefore, L-citrulline may be considered an effective L-arginine and NO supplies which might be expected to have potential for enhancing sport performance. Some studies have found that acute L-citrulline supplementation has no effect on exercise [21, 22]. On the other hand, Bailey et al. [16] showed that 6 days of L-citrulline supplementation improved exercise tolerance. This suggests that chronic L-citrulline supplementation (for about 1 week) is needed to enhance exercise tolerance. However, it is not presently known whether chronic small doses of L-citrulline enhance sport performance. Moreover, to our knowledge, no study has comprehensively evaluated the effects of L-citrulline on endurance exercise performance during simulated competition or on subjective feelings of discomfort associated with exercise in humans. We hypothesized that chronic Lcitrulline administration would enhance performance during simulated competition.

The aim of this study was to investigate the effect of oral supplementation of L-citrulline on cycling time-trial performance in healthy trained men.

\section{Methods}

\section{Subjects}

Twenty-five trained healthy Japanese males volunteered to take part in this double-blind, randomized, placebocontrolled, two-way crossover trial. Because of the crossover design, half of the subjects participated under one condition and half under the other at the same time, with a washout period of 3 weeks. Randomization was conducted by using SAS 9.3 (SAS Institute Inc.). The subjects recruited were aged 20 to 39 years and participated in sport twice a week or more. The sports included athletics (long distance running), baseball, cycling, soccer, triathlon, and skiing. Current smokers, subjects taking medication or dietary supplements for chronic conditions, and subjects with injuries that could interfere with their performance were excluded. The participants' health status was assessed by both physical and laboratory examinations, including an electrocardiogram and blood chemistry panel. Three males were excluded from the analysis because they had colds on the test day. We therefore analyzed a final total of 22 males (mean \pm SD age, $29 \pm 8.4$ years; body mass, $74 \pm 9.4 \mathrm{~kg}$; height, $175 \pm 4.1 \mathrm{~cm}$; body mass index, $24 \pm 3.3 \mathrm{~kg} / \mathrm{m}^{2}$ ). The subjects were instructed not to change their usual training volume or diet during the
7 days of the study. The protocol was conducted according to the Declaration of Helsinki and was approved by the Ethics Committee of Fukuda Clinic (Osaka, Japan). All subjects gave their written informed consent.

\section{Study design}

The study was conducted at Fukuda Clinic (Osaka, Japan). After enrollment, the subjects were randomized into two groups to receive the following treatments once a day for 1 week before the experimental day in a double-blind fashion: 9 capsules consisting of $2.4 \mathrm{~g}$ of Lcitrulline (KYOWA HAKKO BIO CO., Ltd., Tokyo, Japan) or 9 placebo capsules consisting of $2.4 \mathrm{~g}$ of cornstarch (Nippon NSC Co., Ltd., Tokyo, Japan) before bedtime. The indistinguishability of the capsules was confirmed by the Ethics Committee of Fukuda Clinic (Osaka, Japan). The purity of L-citrulline was analyzed by using an amino acid analyzer (L-8900 Hitachi HighTechnologies Corporation, Tokyo, Japan) [23, 24]. There is no recommended dose for L-citrulline intake to enhance sport performance, but a dose of 6 or $8 \mathrm{~g}$ of Lcitrulline malate has been used in other studies $[25,26]$. On the day before each test day, subjects were all given the same meals, which they were required to finish by 9:00 PM; they then fasted overnight. The following morning, blood pressure and heart rate were measured and blood samples were collected. Thereafter, the subjects had breakfast (a rice ball, about $180 \mathrm{kcal}$ ) to provide energy $1 \mathrm{~h}$ before intake of the 9 capsules of placebo or L-citrulline. After the intake of placebo or Lcitrulline, the subjects rested quietly before takingpart in a 4-km cycling time trial (TT). Before the TT, each subject completed a warm-up. The TT was performed on a cycle ergometer (Aerobike 75XL2; Konami Sports \& Life Co., Ltd., Tokyo, Japan) [27] $1 \mathrm{~h}$ after of the intake of placebo or L-citrulline. After the TT, blood samples were collected from the brachial vein. The study design is summarized in Fig. 1.

\section{Physical working capacity test}

Subjects completed a physical working capacity test to determine work rate during the TT. Physical working capacity is an index employed in performance diagnostics to appraise the tested person's aerobic performance capacity. The protocol began with 3 min of 25 -watt (W) cycling, after which 3 min each of $75-\mathrm{W}$ and $125-\mathrm{W}$ cycling was imposed. Physical working capacity at $75 \%$ of the predicted maximum heart rate $\left(\mathrm{PWC}_{75 \% \mathrm{HRmax}}\right)$ was determined from the relationship between HR in the final $30 \mathrm{~s}$ and exercise work load in the abovementioned incremental exercise test. $\mathrm{PWC}_{75 \% \mathrm{HRmax}}$ was evaluated as work load at $75 \%$ of $\mathrm{HR}_{\max }(=220$ - age $)$ [28]. The subjects were then familiarized with the cycle ergometer. 


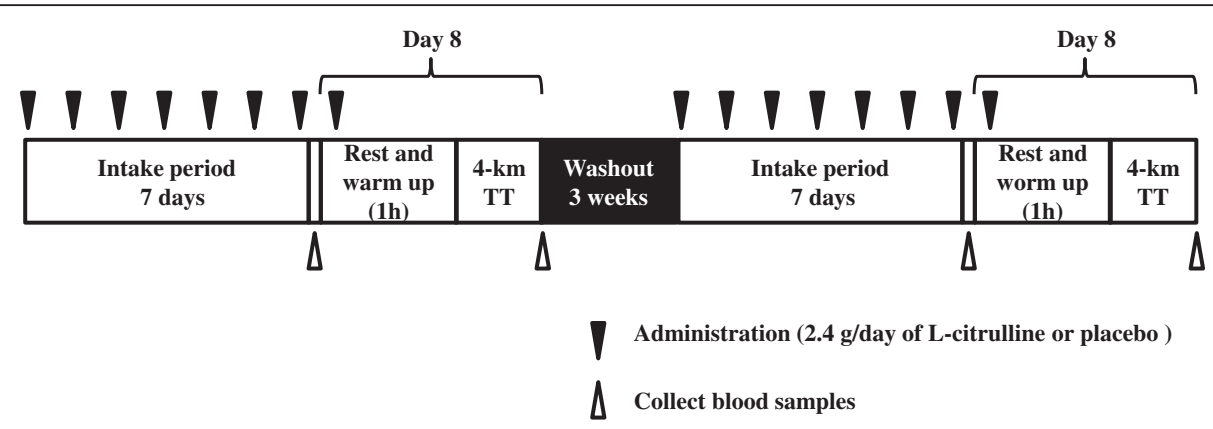

Fig. 1 Study design

\section{Time trial test}

On Day 8 , one hour after intake of $2.4 \mathrm{~g}$ of placebo or Lcitrulline, each subject performed the TT. The work rate of each subject was set at $60 \mathrm{rpm}$ and $\mathrm{PWC}_{75 \% \mathrm{HRmax}}$. Time to complete $4 \mathrm{~km}$ of cycling, power output (PO), $\mathrm{VO}_{2}$, plasma nitrite and nitrate $(\mathrm{NOx})$ levels, plasma amino acid concentrations, and visual analog scale (VAS) scores were evaluated. The computrainer ergometry system recorded PO every $10 \mathrm{~s}$, and these values were averaged for every $0.5 \mathrm{~km}$ completed in the TT to create a PO profile. During the TT, breath-by-breath pulmonary gas exchange and ventilation were measured continuously (Aero Monitor AE-300S, Minato Medical Science Co., Ltd., Osaka, Japan) [29-31]. These data were also used to produce a $\mathrm{PO} / \mathrm{VO}_{2}$ ratio, namely the $\mathrm{PO}$ produced in watts per liter of $\mathrm{O}_{2}$ consumed per min (W/L/min).

\section{Visual analog scale}

Subjects were asked to subjectively rate their degree of discomfort on a VAS from $0 \mathrm{~mm}$ (excellent) to $100 \mathrm{~mm}$ (poor) after the TT. The VAS was originally developed for measuring pain level [32] and has also been used to assess fatigue level [33].

\section{Blood sample analyses}

Blood samples were collected from the brachial vein; $5 \mathrm{~mL}$ was collected each time. Plasma samples were prepared by collecting blood in an EDTA-2Na-containing tube and kept on ice until centrifugation at $1700 \mathrm{~g}$ for $10 \mathrm{~min}$ at $4{ }^{\circ} \mathrm{C}$. Plasma NOx was assayed via the Griess reaction by using a colorimetric assay kit (Nitrate/Nitrite Colorimetric Assay Kit, Cayman, Ann Arbor, MI, USA) [34, 35]. To assess amino acids, the plasma sample was deproteinized with $4 \%$ sulfosalicylic acid (plasma to $20 \%$ sulfosalicylic acid ratio $=0.3: 0.075 \mathrm{~mL}$ ) for $30 \mathrm{~min}$ on ice and then centrifuged at $1700 \mathrm{~g}$ for $10 \mathrm{~min}$ at $4{ }^{\circ} \mathrm{C}$. The supernatant was stored at $-80{ }^{\circ} \mathrm{C}$ until analysis. The concentrations of amino acids (L-valine, L-isoleucine, Lleucine, L-arginine, and L-citrulline) in the plasma were measured with an amino acid analyzer (L-8900 Hitachi High-Technologies Corporation, Tokyo, Japan) [23, 24].

\section{Statistical analyses}

Values are shown as means \pm S.E.M. Paired $t$-tests were used to evaluate the significance of any differences between the placebo and L-citrulline groups. Analyses were performed with SPSS Statistics 22 (IBM Japan, Ltd., Tokyo, Japan). $P$ values of below 0.05 were regarded as statistically significant.

\section{Results}

\section{Blood chemistry}

Plasma amino acid concentrations are summarized in Table 1. Seven days' intake of L-citrulline significantly increased the plasma L-arginine level. On Day 8, plasma L-citrulline and L-arginine levels after TT were significantly higher in the L-citrulline group than in the placebo group. Levels of plasma branched chain amino acids (BCAAs: L-valine, L-isoleucine, L-leucine) were significantly lower at pre-load and post-load in the L-citrulline group than in the placebo group. There was no significant difference in the level of plasma NOx between the placebo and L-citrulline groups (Fig. 2).

\section{Physical performance test}

Mean TT completion times are displayed in Fig. 3, and the accompanying PO profiles are shown in Fig. 4a. LCitrulline supplementation significantly reduced completion time compared with placebo, with a group mean reduction of $1.5 \%$ (placebo: $578 \pm 15$ s, L-citrulline: $569 \pm$ $14 \mathrm{~s}, p<0.05$, Fig. 3). Ingestion of L-citrulline increased mean PO by $2 \%$ (placebo $=189 \pm 5 \mathrm{~W}$ vs. L-citrulline $=$ $193 \pm 5 \mathrm{~W}, p<0.05$, Fig. 4b). There was no significant difference in $\mathrm{VO}_{2}$ response between placebo and Lcitrulline (Table 2). $\mathrm{PO} / \mathrm{VO}_{2}$ tended to be higher in the L-citrulline-supplemented group in three of six elapsed distances $(p<0.1$, Fig. 5). 
Table 1 Plasma amino acid concentration on Day 8

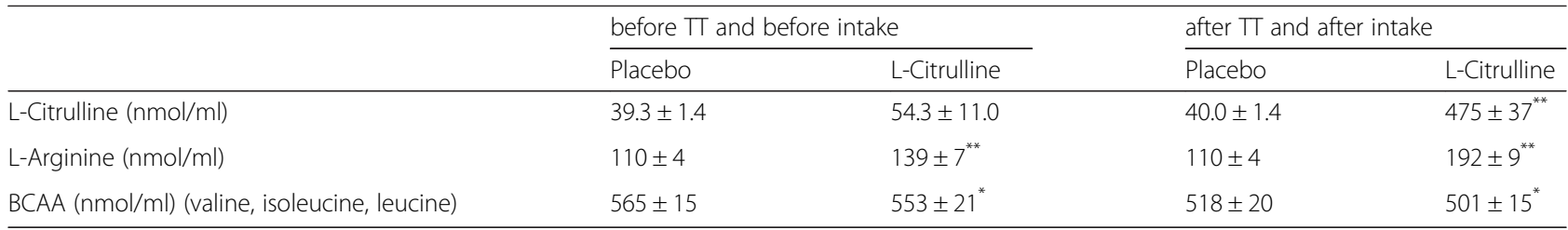

Values are means \pm S.E.M. $n=22,{ }^{*} p<0.05,{ }^{* *} p<0.001$, indicating a significant difference from placebo

\section{Visual analog scale}

L-Citrulline significantly improved subjective feelings of muscle fatigue, and concentration, immediately after exercise (Fig. 6). A marked but not statistically significant improvement in ease of pedaling was observed with L-citrulline supplementation $(p<0.1)$.

\section{Discussion}

We demonstrated that oral supplementation with Lcitrulline at $2.4 \mathrm{~g} /$ day for 7 days significantly increased plasma L-arginine levels. Moreover, intake of L-citrulline for 7 days and I h before the TT significantly increased plasma L-citrulline and L-arginine levels and enhanced cycling TT performance. In addition, subjective feelings of muscle fatigue, and concentration, right after exercise were significantly improved with L-citrulline.

In this human trial, the subjects engaged in TT cycling to allow us to evaluate their exercise performance. Competitive sports typically require athletes to complete a

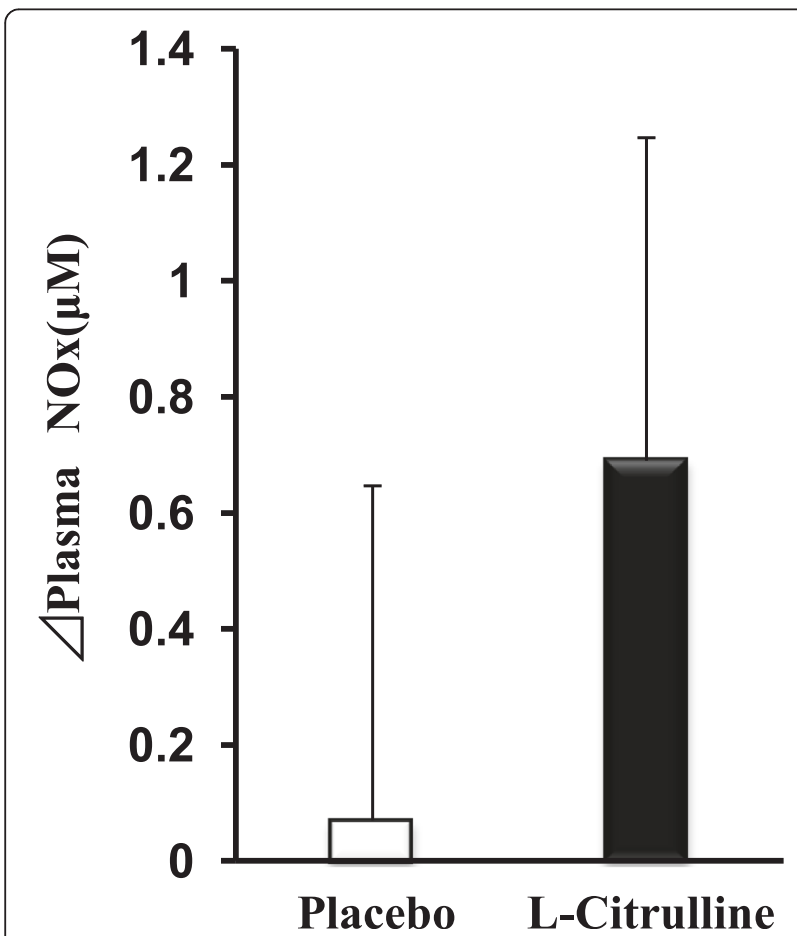

Fig. 2 Changes in plasma NOx before and after a $4 \mathrm{~km} \pi$. Values are means \pm S.E.M. $n=22$ given distance in the shortest possible time. Time-toexhaustion tests are primarily measures of "exercise capacity," and because there is no competitive sports event in which competition is based on time and distance before exhaustion, tests of this type have limited physiological validity [36]. It has also been reported that there is no relationship between measured time-to-exhaustion and actual cycling performance [37]. In contrast, the TT protocol used here has a high level of physiological validity [36], provides an accurate simulation of physiological responses during competition [38], and is well correlated with actual race performance [39]. Therefore, L-citrulline intake might be expected to enhance performance in real competitive sport. We used cornstarch as the placebo and the study design was a double-blind crossover; we expected that these factors would reduce the placebo effect.

The improved TT performance after supplementation with L-citrulline was the consequence of significantly greater $\mathrm{PO}$ for the same $\mathrm{VO}_{2}$. Interestingly, there was a

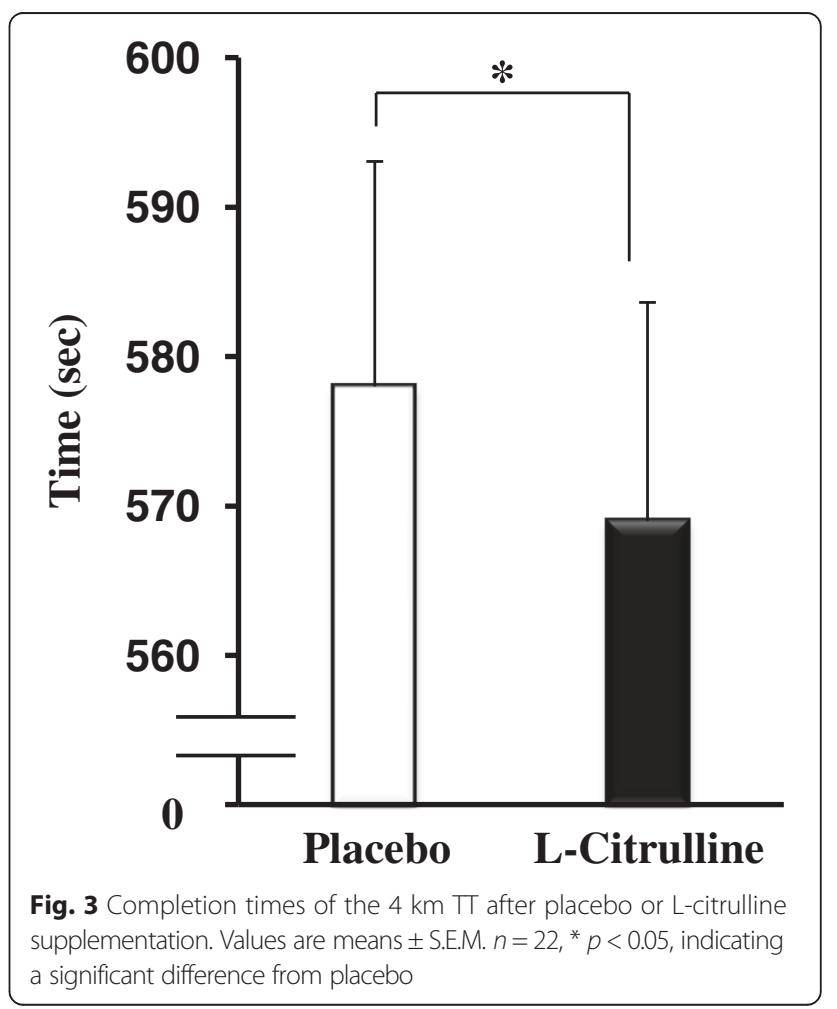



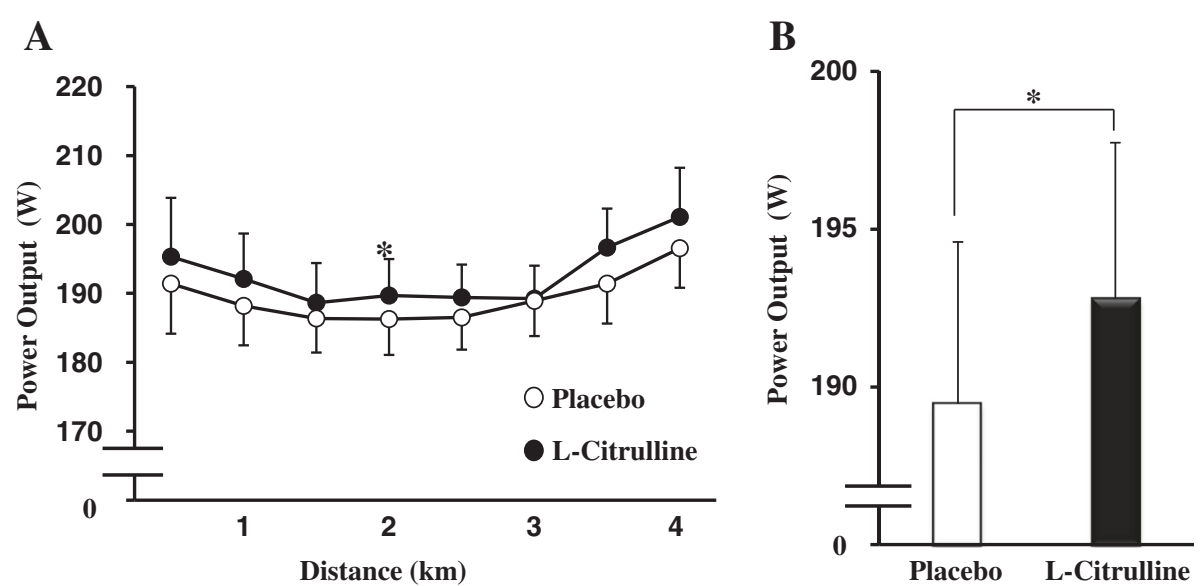

Fig. $4 \mathrm{PO}$ profile during the $4 \mathrm{~km} T(\mathbf{a})$ and mean PO (b) of the $4 \mathrm{~km} T$ after placebo or L-citrulline supplementation. Values are means \pm S.E.M. $n=22 .{ }^{*} p<0.05$, indicating a significant difference from placebo

significant correlation between plasma $\mathrm{NOx}$ and $\mathrm{PO} /$ $\mathrm{VO}_{2}$ after supplementation with L-citrulline but placebo had no correlation (data not shown). This finding suggests that the effects of L-citrulline on $\mathrm{PO} / \mathrm{VO}_{2}$ may have been related to improved plasma NO availability, which in turn may have enhanced sport performance. In sports nutrition, NO-related products are attracting a lot of attention for their ergogenic effects. Many applied studies in humans report that NO improves sports performance. This is because NO is a potential modulator of blood flow, muscle energy metabolism, and mitochondrial respiration during exercise [5, 6, 40, 41]. Dietary supplementation with nitrate reduces the $\mathrm{O}_{2}$ cost of submaximal cycling [6, 42], knee extensor exercise [43], and treadmill walking and running [44]. L-Arginine is the direct precursor of NO via NOS activity. Moreover, oral intake of L-arginine improves sports performance in healthy subjects [45-47]. However, a relatively large dose (6 to $14.2 \mathrm{~g} /$ day) of $\mathrm{L}$-arginine would be required for beneficial effects on sports performance, because Larginine is degraded by arginase in the small intestine

Table $2 \mathrm{VO}_{2}$ profile during the $4 \mathrm{~km} \mathrm{~T}$

\begin{tabular}{lll}
\hline $\begin{array}{l}\text { Distance } \\
(\mathrm{km})\end{array}$ & $\begin{array}{l}\text { Placebo } \\
\mathrm{VO}_{2}(\mathrm{~mL} / \mathrm{min})\end{array}$ & $\begin{array}{l}\text { L-Citrulline } \\
\mathrm{VO}_{2}(\mathrm{~mL} / \mathrm{min})\end{array}$ \\
\hline $0.0 \sim 0.5$ & $1662 \pm 236$ & $1682 \pm 255$ \\
$0.5 \sim 1.0$ & $2396 \pm 311$ & $2400 \pm 341$ \\
$1.0 \sim 1.5$ & $2553 \pm 319$ & $2539 \pm 386$ \\
$1.5 \sim 2.0$ & $2692 \pm 353$ & $2676 \pm 381$ \\
$2.0 \sim 2.5$ & $2777 \pm 346$ & $2801 \pm 369$ \\
$2.5 \sim 3.0$ & $2861 \pm 344$ & $2847 \pm 363$ \\
$3.0 \sim 3.5$ & $2933 \pm 361$ & $2911 \pm 377$ \\
$3.5 \sim 4.0$ & $3005 \pm 381$ & $2971 \pm 397$ \\
\hline
\end{tabular}

Values are means \pm S.E.M. $n=22$ and liver [48-50]. For this reason, some studies have shown no effect of L-arginine on $\mathrm{O}_{2}$ cost and sports performance [51, 52]. In contrast, L-citrulline is not metabolized in the intestine or liver [53]. On entering the kidneys, vascular endothelium, and other tissues, Lcitrulline is readily converted to L-arginine, thus raising plasma and tissue levels of L-arginine and enhancing NO production [10]. We found here that oral intake of L-citrulline increased not only L-citrulline levels but also $\mathrm{L}$-arginine levels. It has been reported that oral supplementation with L-citrulline increases plasma L-arginine levels more effectively than does L-arginine supplementation in healthy subjects [20], and increased plasma Larginine levels before exercise enhance sport performance [16]. However, some studies have found that oral L-citrulline supplementation has no effect on exercise $[21,22]$. This is likely because a single dose of Lcitrulline is insufficient to enhance sport performance. Bailey et al. [16] demonstrated that 6 days of L-citrulline supplementation improved exercise tolerance. These findings suggest that L-citrulline needs to be taken continuously (for about 1 week) to enhance exercise tolerance. This is why we conducted an 8-day trial, which showed positive effects of L-citrulline. The daily dose of L-citrulline in our study was $2.4 \mathrm{~g}$. This seems smaller than those used in other previous studies [16, 21, 22], but 2 to $3 \mathrm{~g}$ of oral L-citrulline has been reported to increase plasma L-arginine levels [20, 54]. Moinard et al. [54] showed that the $C_{\max }$ of plasma L-arginine was $146 \mu \mathrm{M}$ when subjects consumed $2 \mathrm{~g}$ of L-citrulline. In the study by Bailey et al. [16], the L-citrulline group had a mean plasma L-arginine level of $135 \mu \mathrm{M}$ and showed improved exercise performance. Therefore, we had hypothesized that $2.4 \mathrm{~g} /$ day of L-citrulline for 8 days might be enough to increase plasma L-arginine levels such that we would obtain ergogenic effects. In fact, Bailey et al. 


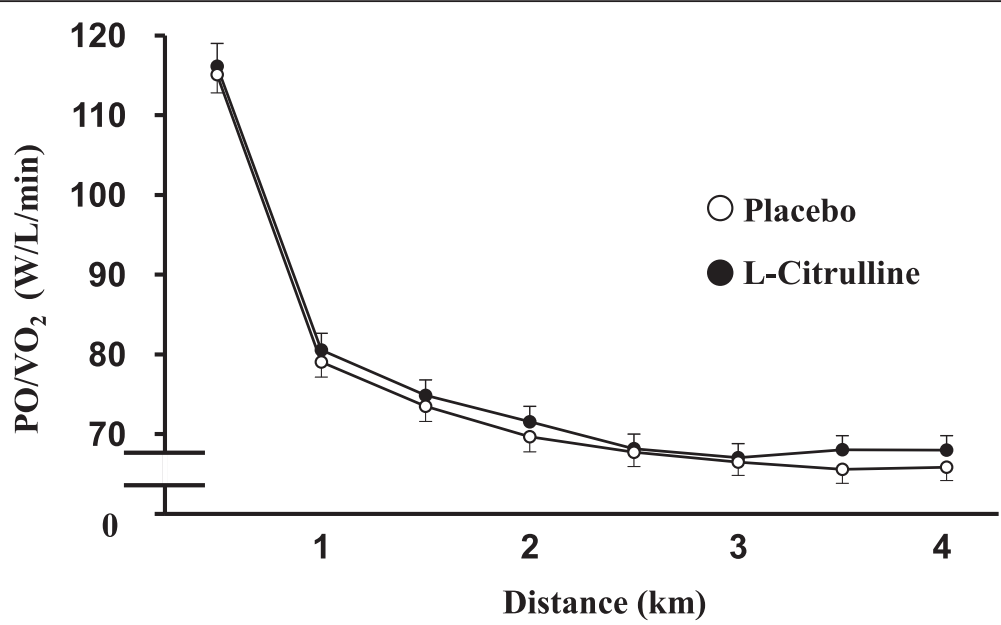

Fig. $5 \mathrm{PO} / \mathrm{NO}_{2}$ during the $4 \mathrm{~km} \pi$ after placebo or L-citrulline supplementation. Values are means \pm S.E.M. $n=22$

reported that the plasma $\mathrm{L}$-arginine level in their Lcitrulline group was about 2.3 times that in their placebo group [16]. On the other hand, our data demonstrated that the plasma L-arginine level in our L-citrulline group was about 1.7 times that in our placebo group. However, our absolute value of plasma L-arginine after intake of L-citrulline was higher than that in the study by Bailey et al. Therefore, $2.4 \mathrm{~g} /$ day of L-citrulline for 8 days is likely enough to obtain ergogenic aid.

We found here that, L-citrulline supplementation significantly increased plasma levels of plasma L-citrulline and L-arginine, which are essential for NO synthesis. In our study the plasma arginine level after supplementation of L-citrulline was as high as that in the study by Bailey et al. [16]. Our results thus suggest that Lcitrulline would enhance sport performance through NO synthesis; however, we were not able to observe an

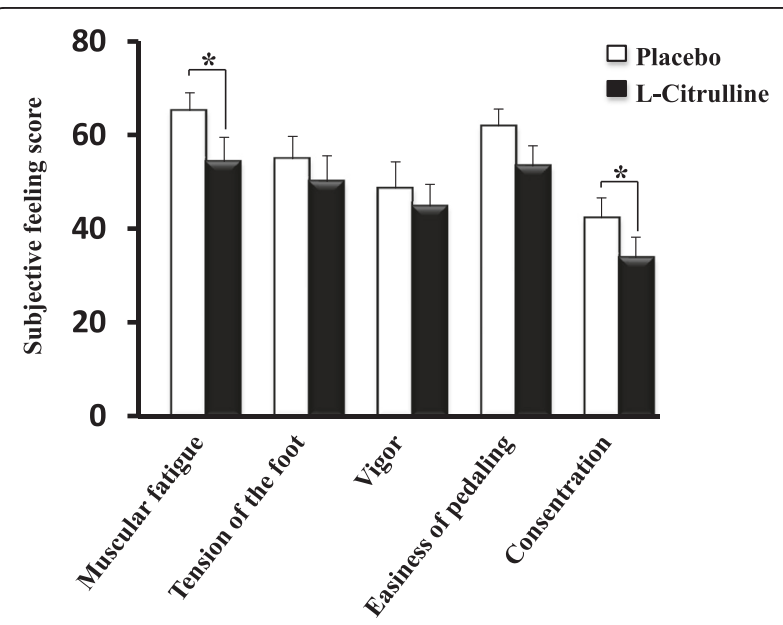

Fig. 6 Subjective feelings immediately after exercise. Values are means \pm S.E.M. $n=22 .{ }^{*} p<0.05$, indicating a significant difference from placebo increase in plasma NOx level. We measured NOx at only two time points: before and after exercise, not during exercise. These evaluation points might not have been suitable for detecting significant between-point differences in NO generation. Chemiluminescence assay is more sensitive than colorimetric assay for detecting NOx. In this study, we measured NOx by colorimetric assay, and it may not have been sensitive enough to detect changes in plasma NOx.

Sureda et al. [26] showed that oral intake of $6 \mathrm{~g}$ of Lcitrulline malate $2 \mathrm{~h}$ before exercise enhances the use of BCAAs, which are metabolized in the muscles to produce energy. In our study, L-citrulline supplementation decreased plasma BCAA levels. These data indicate that L-citrulline promotes the metabolic use of these amino acids as fuel to support muscular exercise. Moreover, Lcitrulline significantly improved subjective feelings of muscular fatigue. BCAA reduces muscle soreness and fatigue $[55,56]$. Furthermore, L-citrulline malate reduces fatigue and post-workout muscle soreness [25]; watermelon juice, which is rich in L-citrulline, also reduces muscle soreness [57]. Our data suggest that L-citrulline has the potential to relieve muscle fatigue. Therefore, the effects of L-citrulline on BCAA utilization and muscular fatigue might also contribute to enhanced sport performance. In addition, the subjective feeling of concentration was significantly improved by oral intake of L-citrulline. Hayashi et al. have reported that L-citrulline improves blood flow [17]. The concentration-enhancing effects of L-citrulline are likely due to enhanced blood flow.

A growing number of sport supplements include Larginine, which is claimed to enhance NO production, despite L-arginine being rapidly metabolized in the small intestine and liver when administered orally. As mentioned above, L-citrulline is a potent precursor of L- 
arginine, and several functional advantages of L-citrulline over L-arginine have been elucidated [17, 20]; moreover, Akashi et al. [58] have revealed that L-citrulline is an efficient hydroxyl radical scavenger. L-arginine tends to be extremely bitter and highly water absorbent, whereas L-citrulline is tasteless, odorless, and nonhygroscopic. It would thus appear that L-citrulline is superior to L-arginine in terms of ease of handling and taste as an ingredient of supplements. L-Citrulline is present in large quantities in watermelon but is not abundant in other fruits, vegetables, meat, or fish because it is a free amino acid. It is difficult to obtain L-citrulline from a conventional diet in sufficient amounts to enhance sports performance. Therefore, it may be beneficial to take a few tablets of L-citrulline before exercise as an ergogenic aid.

Our study had several limitations. We instructed the subjects not to change their training volumes and to eat their usual diets during the 7 days of the study. However, we did not make the training volumes and diets identical among the subjects, with the exception of dinner on the evening before the test day and breakfast on the test day. Some of the subjects' performances may have been affected by intense training sessions in the 2 days before the trials. Here, we conducted a double-blind randomized placebo-controlled two-way crossover study in 22 subjects; in future, an additional, larger-scale study will be needed to verify our findings.

\section{Conclusions}

We conclude that oral L-citrulline supplementation enhances cycling time trial performance. Moreover, Lcitrulline improves subjective feelings (e.g. of muscle soreness) after performance. These data, taken together, suggest that L-citrulline is a promising amino acid for enhancing sport performance.

\section{Abbreviations}

BCAAs: branched chain amino acids; eNOS: endothelial NO synthase; NO: nitric oxide; NOS: NO synthase; NOx: nitrite and nitrate; $\mathrm{PO}_{\mathrm{NO}}$ : power output $/ \mathrm{VO}_{2}$ ratio; $\Pi$ : time trial; VAS: Visual Analog Scale.

\section{Competing interests}

This study was conducted in research funding by KYOWA HAKKO BIO CO., LTD. Takashi Suzuki, Masahiko Morita and Ayako Kamimura are employee of KYOWA HAKKO BIO CO., LTD. The other co-author declare no conflict of interests.

\section{Authors' contributions}

TS carried out study design and drafted the manuscript. MM made contributions to design, helped to draft the manuscript. YK made contributions to conception and design. AK supervised manuscript preparation. All authors read and approved the final manuscript.

\section{Author details}

${ }^{1}$ Healthcare Products Development Center, KYOWA HAKKO BIO CO., LTD., 2 Miyukigaoka, Tsukuba, Ibaraki 305-0841, Japan. ${ }^{2}$ Laboratory of Pharmacognosy, School of Pharmaceutical Sciences, Kitasato University, 5-9-1, Shirokane, Minato-ku, Tokyo 108-0861, Japan.
Received: 11 September 2015 Accepted: 12 February 2016

Published online: 19 February 2016

\section{References}

1. Albrecht EW, Stegeman CA, Heeringa P, Henning $\mathrm{RH}$, Van Goor H. Protective role of endothelial nitric oxide synthase. J Pathol. 2003;199:8-17.

2. Petroczi A, Naughton DP. Potentially fatal new trend in performance enhancement: a cautionary note on nitrite. J Int Soc Sports Nutr. 2010;7:25.

3. Bescos R, Sureda A, Tur JA, Pons A. The effect of nitric-oxide-related supplements on human performance. Sports Med. 2012;42:99-117.

4. Jones AM. Dietary nitrate supplementation and exercise performance. Sports Med. 2014;44 Suppl 1:S35-45.

5. Shen W, Xu X, Ochoa M, Zhao G, Wolin MS, Hintze TH. Role of nitric oxide in the regulation of oxygen consumption in conscious dogs. Circ Res. 1994;75:1086-95.

6. Bailey SJ, Winyard P, Vanhatalo A, Blackwell JR, Dimenna FJ, Wilkerson DP, et al. Dietary nitrate supplementation reduces the $\mathrm{O} 2$ cost of low-intensity exercise and enhances tolerance to high-intensity exercise in humans. J Appl Physiol (1985). 2009;107:1144-55.

7. Cermak NM, Gibala MJ, van Loon LJ. Nitrate supplementation's improvement of 10-km time-trial performance in trained cyclists. Int J Sport Nutr Exerc Metab. 2012;22:64-71.

8. Lansley KE, Winyard PG, Bailey SJ, Vanhatalo A, Wilkerson DP, Blackwell JR, et al. Acute dietary nitrate supplementation improves cycling time trial performance. Med Sci Sports Exerc. 2011;43:1125-31.

9. Wilkerson DP, Hayward GM, Bailey SJ, Vanhatalo A, Blackwell JR, Jones AM. Influence of acute dietary nitrate supplementation on 50 mile time trial performance in well-trained cyclists. Eur J Appl Physiol. 2012;112:4127-34.

10. Curis E, Nicolis I, Moinard C, Osowska S, Zerrouk N, Benazeth S, et al. Almost all about citrulline in mammals. Amino Acids. 2005;29:177-205.

11. Schmidt HH, Nau H, Wittfoht W, Gerlach J, Prescher KE, Klein MM, et al. Arginine is a physiological precursor of endothelium-derived nitric oxide. Eur J Pharmacol. 1988;154:213-6.

12. Hecker M, Sessa WC, Harris HJ, Anggard EE, Vane JR. The metabolism of Larginine and its significance for the biosynthesis of endothelium-derived relaxing factor: cultured endothelial cells recycle $L$-citrulline to $L$-arginine. Proc Natl Acad Sci U S A. 1990;87:8612-6.

13. Ochiai M, Hayashi T, Morita M, Ina K, Maeda M, Watanabe F, et al. Shortterm effects of L-citrulline supplementation on arterial stiffness in middleaged men. Int J Cardiol. 2012;155:257-61.

14. Hotta Y, Shiota A, Kataoka T, Motonari M, Maeda Y, Morita M, et al. Oral L-citrulline supplementation improves erectile function and penile structure in castrated rats. Int J Urol. 2014;21:608-12.

15. Yabuki Y, Shioda N, Yamamoto Y, Shigano M, Kumagai K, Morita M, et al. Oral L-citrulline administration improves memory deficits following transient brain ischemia through cerebrovascular protection. Brain Res. 2013;1520:157-67.

16. Bailey SJ, Blackwell JR, Lord T, Vanhatalo A, Winyard PG, Jones AM. L-citrulline supplementation improves $\mathrm{O} 2$ uptake kinetics and high-intensity exercise performance in humans. J Appl Physiol (1985). 2015;19(4):385-95. doi:10.1152/ japplphysiol.00192.2014.

17. Hayashi T, Juliet PA, Matsui-Hirai H, Miyazaki A, Fukatsu A, Funami J, et al. I-Citrulline and I-arginine supplementation retards the progression of high-cholesterol-diet-induced atherosclerosis in rabbits. Proc Natl Acad Sci U S A. 2005:102:13681-6.

18. Romero MJ, Platt DH, Tawfik HE, Labazi M, El-Remessy AB, Bartoli M, et al. Diabetes-induced coronary vascular dysfunction involves increased arginase activity. Circ Res. 2008;102:95-102.

19. Wu G, Collins JK, Perkins-Veazie P, Siddiq M, Dolan KD, Kelly KA, et al. Dietary supplementation with watermelon pomace juice enhances arginine availability and ameliorates the metabolic syndrome in Zucker diabetic fatty rats. J Nutr. 2007;137:2680-5

20. Schwedhelm E, Maas R, Freese R, Jung D, Lukacs Z, Jambrecina A, et al. Pharmacokinetic and pharmacodynamic properties of oral L-citrulline and L-arginine: impact on nitric oxide metabolism. Br J Clin Pharmacol. 2008;65:51-9.

21. Cutrufello PT, Gadomski SJ, Zavorsky GS. The effect of I-citrulline and watermelon juice supplementation on anaerobic and aerobic exercise performance. J Sports Sci. 2015;33:1459-66.

22. Hickner RC, Tanner CJ, Evans CA, Clark PD, Haddock A, Fortune C, et al. $\mathrm{L}$-citrulline reduces time to exhaustion and insulin response to a graded exercise test. Med Sci Sports Exerc. 2006;38:660-6.

23. Heo KN, Hong EC, Kim CD, Kim HK, Lee MJ, Choo HJ, et al. Growth performance, carcass yield, and quality and chemical traits of meat from 
commercial korean native ducks with 2-way crossbreeding. Asian-Australas J Anim Sci. 2015;28:382-90.

24. Watts ST. Advancements in Amino Acid Analysis: Introduction of the New Hitachi L-8900 Amino Acid Analyzer. LCGC N Am. 2006;24(Suppl):17-20.

25. Perez-Guisado J, Jakeman PM. Citrulline malate enhances athletic anaerobic performance and relieves muscle soreness. J Strength Cond Res. 2010;24:1215-22.

26. Sureda A, Cordova A, Ferrer MD, Perez G, Tur JA, Pons A. L-citrulline-malate influence over branched chain amino acid utilization during exercise. Eur J Appl Physiol. 2010;110:341-51.

27. Sugino T, Aoyagi S, Shirai T, Kajimoto Y, Kajimoto O. Effects of citric acid and I-carnitine on physical fatigue. J Clin Biochem Nutr. 2007;41:224-30.

28. Nagashima J, Musha H, Takada H, Takagi K, Mita T, Mochida T, et al. Threemonth exercise and weight loss program improves heart rate recovery in obese persons along with cardiopulmonary function. J Cardiol. 2010;56:79-84.

29. Abe T, Fujita S, Nakajima T, Sakamaki M, Ozaki H, Ogasawara R, et al. Effects of Low-intensity cycle training with restricted Leg blood flow on thigh muscle volume and VO2MAX in young Men. J Sports Sci Med. 2010;9:452-8.

30. Nagai N, Sakane N, Tsuzaki K, Moritani T. UCP1 genetic polymorphism (-3826 A/G) diminishes resting energy expenditure and thermoregulatory sympathetic nervous system activity in young females. Int J Obes (Lond). 2011;35:1050-5.

31. Yamada K, Suda T, Komoro YS, Kanefuji T, Kubota T, Murayama T, et al. Low fat intake is associated with pathological manifestations and poor recovery in patients with hepatocellular carcinoma. Nutr J. 2013;12:79.

32. Maxwell C. Sensitivity and accuracy of the visual analogue scale: a psychophysical classroom experiment. Br J Clin Pharmacol. 1978;6:15-24.

33. Leung AW, Chan CC, Lee AH, Lam KW. Visual analogue scale correlates of musculoskeletal fatigue. Percept Mot Skills. 2004;99:235-46.

34. Mayo JN, Beard Jr RS, Price TO, Chen CH, Erickson MA, Ercal N, et al. Nitrative stress in cerebral endothelium is mediated by mGluR5 in hyperhomocysteinemia. J Cereb Blood Flow Metab. 2012;32:825-34.

35. Tuzcu H, Aslan I, Aslan M. The effect of high-dose insulin analog initiation therapy on lipid peroxidation products and oxidative stress markers in type 2 diabetic patients. Oxid Med Cell Longev. 2013;2013:513742.

36. Currell K, Jeukendrup AE. Validity, reliability and sensitivity of measures of sporting performance. Sports Med. 2008;38:297-316.

37. Laursen PB, Rhodes EC, Langill RH, McKenzie DC, Taunton JE. Relationship of exercise test variables to cycling performance in an Ironman triathlon. Eur J Appl Physiol. 2002;87:433-40.

38. Foster C, Green MA, Snyder AC, Thompson NN. Physiological responses during simulated competition. Med Sci Sports Exerc. 1993;25:877-82.

39. Palmer GS, Dennis SC, Noakes TD, Hawley JA. Assessment of the reproducibility of performance testing on an air-braked cycle ergometer. Int J Sports Med. 1996;17:293-8.

40. Tschakovsky ME, Joyner MJ. Nitric oxide and muscle blood flow in exercise. Appl Physiol Nutr Metab. 2008:33:151-61.

41. Larsen FJ, Schiffer TA, Borniquel S, Sahlin K, Ekblom B, Lundberg JO, et al. Dietary inorganic nitrate improves mitochondrial efficiency in humans. Cell Metab. 2011;13:149-59.

42. Larsen FJ, Weitzberg E, Lundberg JO, Ekblom B. Effects of dietary nitrate on oxygen cost during exercise. Acta Physiol (Oxf). 2007;191:59-66.

43. Bailey SJ, Fulford J, Vanhatalo A, Winyard PG, Blackwell JR, DiMenna FJ, et al. Dietary nitrate supplementation enhances muscle contractile efficiency during knee-extensor exercise in humans. J Appl Physiol (1985). 2010;109:135-48.

44. Lansley KE, Winyard PG, Fulford J, Vanhatalo A, Bailey SJ, Blackwell JR, et al. Dietary nitrate supplementation reduces the $\mathrm{O} 2$ cost of walking and running: a placebo-controlled study. J Appl Physiol (1985). 2011;110:591-600.

45. Campbell B, Roberts M, Kerksick C, Wilborn C, Marcello B, Taylor L, et al. Pharmacokinetics, safety, and effects on exercise performance of L-arginine alpha-ketoglutarate in trained adult men. Nutrition. 2006;22:872-81.

46. Fricke O, Baecker N, Heer M, Tutlewski B, Schoenau E. The effect of L-arginine administration on muscle force and power in postmenopausal women. Clin Physiol Funct Imaging. 2008;28:307-11.

47. Koppo K, Taes YE, Pottier A, Boone J, Bouckaert J, Derave W. Dietary arginine supplementation speeds pulmonary VO2 kinetics during cycle exercise. Med Sci Sports Exerc. 2009;41:1626-32.

48. Hayashi T, Esaki T, Sumi D, Mukherjee T, Iguchi A, Chaudhuri G. Modulating role of estradiol on arginase II expression in hyperlipidemic rabbits as an atheroprotective mechanism. Proc Natl Acad Sci U S A. 2006;103:10485-90.
49. Munder M. Arginase: an emerging key player in the mammalian immune system. Br J Pharmacol. 2009;158:638-51.

50. Castillo L, Chapman TE, Sanchez M, Yu YM, Burke JF, Ajami AM, et al. Plasma arginine and citrulline kinetics in adults given adequate and arginine-free diets. Proc Natl Acad Sci U S A. 1993;90:7749-53.

51. Alvares TS, Conte CA, Paschoalin VM, Silva JT, Meirelles Cde M, Bhambhani YN, et al. Acute l-arginine supplementation increases muscle blood volume but not strength performance. Appl Physiol Nutr Metab. 2012;37:115-26.

52. Vanhatalo A, Bailey SJ, DiMenna FJ, Blackwell JR, Wallis GA, Jones AM. No effect of acute L-arginine supplementation on $\mathrm{O}(2)$ cost or exercise tolerance. Eur J Appl Physiol. 2013;113:1805-19.

53. Romero MJ, Platt DH, Caldwell RB, Caldwell RW. Therapeutic use of citrulline in cardiovascular disease. Cardiovasc Drug Rev. 2006;24:275-90.

54. Moinard C, Nicolis I, Neveux N, Darquy S, Benazeth S, Cynober L. Dose-ranging effects of citrulline administration on plasma amino acids and hormonal patterns in healthy subjects: the Citrudose pharmacokinetic study. Br J Nutr. 2008;99:855-62.

55. Kim DH, Kim SH, Jeong WS, Lee HY. Effect of BCAA intake during endurance exercises on fatigue substances, muscle damage substances, and energy metabolism substances. J Exerc Nutrition Biochem. 2013;17:169-80.

56. Matsumoto K, Koba T, Hamada K, Sakurai M, Higuchi T, Miyata H. Branched-chain amino acid supplementation attenuates muscle soreness, muscle damage and inflammation during an intensive training program. J Sports Med Phys Fitness. 2009:49:424-31.

57. Tarazona-Diaz MP, Alacid F, Carrasco M, Martinez I, Aguayo E. Watermelon juice: potential functional drink for sore muscle relief in athletes. J Agric Food Chem. 2013;61:7522-8.

58. Akashi K, Miyake C, Yokota A. Citrulline, a novel compatible solute in drought-tolerant wild watermelon leaves, is an efficient hydroxyl radical scavenger. FEBS Lett. 2001;508:438-42.

\section{Submit your next manuscript to BioMed Central and we will help you at every step:}

- We accept pre-submission inquiries

- Our selector tool helps you to find the most relevant journal

- We provide round the clock customer support

- Convenient online submission

- Thorough peer review

- Inclusion in PubMed and all major indexing services

- Maximum visibility for your research

Submit your manuscript at www.biomedcentral.com/submit
(O) BioMed Central 